\title{
Transferring voice effects in recognition memory from remembering to knowing
}

\author{
IRENE KARAYIANNI and JOHN M. GARDINER \\ University of Sussex, Brighton, England
}

\begin{abstract}
In five experiments, we investigated the effects of voice congruency (same vs. different voices at study and at test) on remembering and knowing in recognition memory. With low- and medium-frequency three- or four-syllable words, a voice congruency effect occurred only in remembering. With nonwords, voice congruency effects occurred both in remembering and in knowing. With nonwords and divided attention at study, the voice congruency effect transferred almost completely from remembering to knowing. By showing a transfer of effects from remembering to knowing as encoding became more impoverished, these findings support a distinctiveness/fluency account of remembering and knowing as well as the theory that remembering and knowing indicate retrieval of events from episodic and semantic memory systems, respectively.
\end{abstract}

Tulving (1985) demonstrated that participants can distinguish between two subjective states of awareness during retrieval: remembering and knowing. In doing so, he introduced the remember/know paradigm. This paradigm has been most widely used in recognition memory, in which, for each test item that participants claim to recognize, they have to report their state of awareness. When recognition is accompanied by the conscious recollection of the item's earlier occurrence in a study list, participants are told to make a "remember" response. When recognition is not accompanied by recollective experiences but is associated only with feelings of familiarity or knowing, participants are told to make a "know" response.

In Tulving's $(1983,1985)$ theory, remembering and knowing are expressions of autonoetic and noetic consciousness, respectively, which in turn characterize retrieval from episodic and semantic memory systems. Autonoetic consciousness is expressed by awareness of oneself in relation to time and place and is manifested in detailed recollective experiences. Remembering refers to mental time travel, a mental reliving of something that happened in one's personal past. Noetic consciousness is expressed by a more abstract awareness of the past that does not include any recollective experiences of oneself in relation to time and place. Knowing refers to being aware of past experiences simply as facts, in an impersonal way. In Tulving's (1995) SPI model, encoding is serial (S) in that events can be encoded into episodic memory only after having been en-

The experiments reported in this article form part of the first author's $\mathrm{PhD}$ thesis, which is in preparation. Completion of the article was facilitated by Grant 000-22-0015 from the Economic and Social Research Council, U.K. Correspondence concerning this article should be addressed to J. Gardiner, Department of Psychology, University of Sussex, Brighton BN1 9QH, England (e-mail: j.m.gardiner@sussex.ac.uk). coded into semantic memory; storage is parallel $(\mathrm{P})$ in that events can be stored in both systems; and retrieval is independent (I) in that events can be retrieved independently from either system.

There is now considerable evidence of functional independence between remembering and knowing in recognition memory in the form of systematic dissociations or associations among various independent variables (for reviews, see Gardiner, 2001; Gardiner \& Richardson-Klavehn, 2000). Some independent variables, particularly those that engage more conceptual or elaborative processing, increase remembering only: for example, deep versus shallow level of processing (Gardiner, 1988; Gardiner, Gregg, Mashru, \& Thaman, 2001), generating versus reading (Gardiner, 1988), and elaborative versus maintenance rehearsal (Gardiner, Gawlik, \& Richardson-Klavehn, 1994). Other variables that engage more perceptual processing increase only knowing: for example, identical versus unrelated masked test primes (Rajaram, 1993) and same versus different modality between study and test following a highly perceptual orienting task (Gregg \& Gardiner, 1994). Yet other variables have opposite effects on the two responses, such as studying words versus nonwords in mixed lists. In comparison with words, nonwords give rise to more knowing and less remembering (Gardiner \& Java, 1990; Rajaram, Hamilton, \& Bolton, 2002). Rating personality traits with reference to oneself, rather than for their positive or negative valence, gives rise to more remembering and less knowing (see, e.g., Conway, Dewhurst, Pearson, \& Sapute, 2001). Finally, some variables increase both remembering and knowing in parallel: for example, having three successive study trials instead of only one, at least under some circumstances (Gardiner, Kaminska, Dixon, \& Java, 1996) or having long versus short response deadlines (Gardiner, Ramponi, \& Richardson-Klavehn, 1999). In Tulving's account (see Tulving, 2002, for a recent review), these find- 
ings indicate dissociable contributions from episodic and semantic memory to the recognition of studied events.

Rajaram (1993) developed an alternative account derived from the transfer-appropriate processing framework (see, e.g., Roediger, 1990) to explain how different experimental manipulations affect remembering and knowing. Initially, and in line with the initial findings, Rajaram (1993) suggested that remembering was influenced by conceptual processing and that knowing depended on perceptual processing. In a revision of her account, the distinctiveness/ fluency model (Rajaram, 1996), she proposed instead that the relation between the states of awareness and the underlying conceptual or perceptual processing is orthogonal: Remembering reflects distinctiveness of processing and knowing reflects processing fluency, regardless of whether that processing is more conceptual or more perceptual. This distinctiveness/fluency model followed evidence that remembering is sometimes influenced by perceptual as well as by conceptual factors, and that knowing is sometimes influenced by conceptual factors as well as by perceptual ones.

For example, Rajaram (1996) employed a perceptual manipulation-namely, size changes in pictorial material between study and test. Participants studied a list of line drawings, half of which were in a large size and half in a small size. At test, half the studied items changed size, and half stayed the same size. The beneficial effects of size congruency on recognition memory occurred only in "remember" responses. In another experiment, Rajaram (1998) manipulated an additional perceptual variable, orthographic word distinctiveness, which also benefited recognition only in "remember" responses. Conversely, there have been instances in which conceptual manipulations affect knowing: for example, grouping faces according to their similarities with respect to semantic memory schemas, such as whether they looked like faces of partygoers (Mäntylä, 1997), or comparing conceptually related test primes with unrelated test primes (Rajaram \& Geraci, 2000). These findings support the distinctiveness/fluency model, which can be viewed as being complementary to Tulving's $(1983,1985)$ systems theory.

A number of other theoretical models have been applied to remembering and knowing. Prominent among them is the independence remember/know model, according to which remembering and knowing reflect the independent processes of recollection and familiarity, respectively (see, e.g., Jacoby, Yonelinas, \& Jennings, 1997). In this model, "remember" and "know" responses are used as a basis for estimating the underlying processes of recollection and familiarity, and, because the processes are independent but the responses are exclusive, estimates of familiarity are obtained by dividing the proportions of "know" responses by one minus the proportions of "remember" responses. This approach has the advantage of relating findings from the remember/know procedure to those from the process dissociation procedure (Jacoby, 1991), which also provides estimates of recollection and familiarity (see Yonelinas, 2002). However, if the research goal is to determine how particular conditions or particular effects influence the reported states of awareness, as was the goal in the present work, then the appropriate measure remains that of knowing, the state of awareness indexed directly by "know" responses. In line with this goal, we use the terms knowing and remembering strictly to refer to the two states of awareness.

Yet another theoretical approach has been to suggest that remembering and knowing merely represent more stringent and more lenient response criteria, respectively, along a continuum of trace strength, and that the responses can therefore be modeled by signal detection theory (see, e.g., Donaldson, 1996; Hirshman \& Master, 1997; Inoue \& Bellezza, 1998). These memory-strength/decision process accounts have now been shown not to provide an adequate general account of remembering and knowing (see, e.g., Conway et al., 2001; Gardiner, Ramponi, \& RichardsonKlavehn, 2002), although more sophisticated dualcomponent accounts based on a similar kind of approach are proving more successful (e.g., Rotello, Macmillan, \& Reeder, in press; Yonelinas, Dobbins, Szymanski, Dhaliwal, \& King, 1996). Nonetheless, as Hirshman and his colleagues have suggested (Hirshman, Fisher, Henthorn, Arndt, \& Passannante, 2002; Hirshman, Lanning, Master, $\&$ Henzler, 2002), there may still be some theoretical value in applying the single trace-strength model in some circumstances-for example, to obtain evidence for whether one can discount an explanation in terms of decision processes in those particular circumstances.

Set against this theoretical background, in the experiments we describe we aimed to test the generality of some new findings reported by Gardiner et al. (2001), who had discovered that certain effects in recognition memory transfer from remembering to knowing with relatively impoverished encoding conditions. Gardiner et al. (2001) had followed up Rajaram's (1996) study by investigating the effects of encoding conditions on the occurrence of size congruency effects in remembering. The main finding was that size congruency effects occurred in knowing rather than in remembering, with more impoverished encoding conditions. Size congruency effects occurred in remembering with undivided attention or with a deeper level of processing, replicating Rajaram's (1996) results, but, with divided attention or a shallow level of processing, similar size congruency effects instead occurred in knowing.

Those results strengthen the argument that the relation between conceptual/perceptual processes and the two states of awareness is orthogonal, because they showed that similar perceptual effects may occur either in remembering or in knowing, depending on encoding conditions. Presumably, with relatively impoverished encoding conditions, there is less opportunity for more elaborative and distinctive encoding. By the same token, those results are also consistent with Tulving's (1995) SPI model, suggesting, as they do, that with such relatively impoverished encoding conditions events may be encoded into the semantic system without being encoded into the episodic system. Evidence reported by Mangels, Picton, and Craik (2001), 
who compared divided with undivided attention at encoding in an event-related potential study of remembering and knowing, provides further support for this interpretation. They concluded that although fairly minimal attention was sufficient for familiarity-based recognition, additional elaborative processing (involving more prolonged interactions between frontal and posterior regions of the brain) was necessary for conscious recollection.

In the present experiments, we investigated voice congruency effects in word recognition. Voice congruency effects are defined by superior recognition of words spoken by the same voice at study and at test in comparison with recognition of words spoken by different voices at study and at test. Such voice effects in recognition memory have been reported in quite a few previous studies, although they have not always been obtained reliably in individual experiments (e.g., Church \& Schacter, 1994; Craik \& Kirsner, 1974; Goldinger, 1996; Palmeri, Goldinger, \& Pisoni, 1993; Pilotti, Bergman, Gallo, Sommers, \& Roediger, 2000; Pilotti, Gallo, \& Roediger, 2000; Schacter \& Church, 1992; Sheffert \& Fowler, 1995). The purpose of the present research, however, was not to elucidate further the circumstances under which voice effects are obtained but, rather, to determine how such effects relate to remembering and knowing. The hypothesis was that voice congruency effects would occur in remembering with more optimal encoding conditions and in knowing with less optimal encoding conditions.

\section{Overview of the Experiments}

In each of five experiments, voice congruency was manipulated using just two voices, a male voice and a female voice. Experiment 1 was designed simply to replicate the voice congruency effect under normal learning conditions using relatively lengthy, low-frequency words and a study task, in which participants rated the clarity of their pronunciation to maximize the salience of the vocal cues. Under these conditions, it was expected that voice congruency effects would occur in remembering (cf. Gardiner et al., 2001; Rajaram, 1996). In Experiments 2 and 3, nonwords were used instead of words because, even under normal learning conditions, they provide less opportunity than words do for meaningful, elaborative encoding and give rise to less remembering (Gardiner \& Java, 1990; Rajaram et al., 2002). For those reasons, nonword recognition might be more reliant on vocal cues, and voice congruency effects might occur in knowing. Experiment 3 was designed to provide a replication of Experiment 2. In Experiment 4, nonwords were also used, but the study lists were presented in conjunction with a divided-attention task to further reduce the opportunity for elaborative encoding and, hence, for remembering. For that reason, it was expected that voice congruency effects would be even more restricted to knowing. Thus, the hypothesis-testing strategy across the sequence of experiments was to render encoding conditions gradually more impoverished, first by using less meaningful items and then by allowing only fairly minimal attention to them at study.
Experiment 5 was designed to replicate Experiment 4, but with the addition of reports of a third state of awareness: that of guessing. Rajaram (1996) had used the original remember/know paradigm, in which only remembering or knowing are reported, as did Gardiner et al. (2001) in following up her study. We did so in the present experiments too-with the exception of Experiment 5- simply to maintain continuity with those previous studies, because we were seeking to replicate and extend the kinds of effects they obtained. But in quite a few recent studies, "guess" responses have been added to the remember/ know paradigm, partly for methodological reasons (see, e.g., Gardiner \& Conway, 1999; Gardiner et al., 2002; Gardiner \& Richardson-Klavehn, 2000). Allowing reports of guessing has the advantage of reducing false alarm rates, especially in "know' responses, thereby revealing effects of memory more clearly.

\section{GENERAL METHOD}

\section{Participants}

A total of 112 students from Sussex University participated in the experiments. There were 32 participants in Experiment 1, 32 in Experiment 2, and 16 in each of Experiments 3, 4, and 5. They were tested individually and were paid for their participation. None of the participants knew how to speak Greek (Greek words were used as English nonwords in the later experiments).

\section{Design and Materials}

In each experiment, voice congruency between study and test was the single within-participants variable: same versus different (male vs. female) voice between study and test. Study lists consisted of 30 English words (Experiment 1) or 30 English nonwords (Experiments 2-5) spoken in a male voice and 30 words or 30 nonwords spoken in a female voice. Test lists consisted of 60 studied items randomly mixed with 60 similar, unstudied items, 30 of which were spoken in the male voice and 30 in the female voice. Half of the studied items in the test list were spoken in the same voice as at study (i.e., male-male and female-female), and half were spoken in the alternate voice (i.e., male-female and female-male). Full counterbalancing with respect to voice and to study/test conditions, including studied versus unstudied status, resulted in two versions of the test lists and four versions of the study lists.

The materials in Experiment 1 were 120 three- or four-syllable medium- and low-frequency English nouns. They were selected from the Medical Research Council (MRC) psycholinguistic database and had a mean frequency count of 5 according to Kučera and Francis's (1967) norms. Examples of the words are kaleidoscope, roundabout, battalion, and poignancy. The materials in Experiments 2-5 were 120 two-syllable Greek words, which served as pronounceable English nonwords, given that none of the participants knew how to speak Greek. Examples of these Greek words, corresponding to the way in which they were pronounced, are melo, neesee, roba, and vode.

\section{Procedure}

Each of the words and nonwords was recorded twice, once in the male voice and once in the female voice. These items were digitally recorded at a 44.1-kHz 8-bit sampling rate using Cubase VST sound engineering software. They were normalized for volume and amplitude levels. The items were then recorded on a $\mathrm{CD}$ to be played back to the participants on headphones via an Apple Macintosh (iMac) computer with OS 9, which controlled the presentation and timing. Study lists were presented at a rate of $4 \mathrm{sec}$ per item. Test lists were presented at a rate of $5 \mathrm{sec}$ per item. 
At study, the participants were told that they would hear a list of words (Experiment 1) or nonwords (Experiments 2-5), some of which would be spoken in a male voice and others in a female voice, and that they should pay attention to them because an unspecified memory test would follow. In Experiments 1-3, the participants had to rate each item they heard for the clarity of its pronunciation using a scale ranging from 1 (very unclear) to 5 (very clear). They recorded their ratings on a response sheet with 60 numbered rows. For Experiments 4 and 5, the participants had to perform a divided attention task while listening to the study list. This task involved monitoring a series of random pairs of numbers presented on a screen and reporting whether both numbers were odd, both numbers were even, or one was odd and one was even. These numbers were presented at a rate of $3 \mathrm{sec}$ per pair.

The recognition test began 10 min after the study phase. During this interval, the participants were given instructions for the test and on how they should make remember and know judgments. They were told that they would listen again to a series of words (Experiment 1) or nonwords (Experiments 2-5) spoken in either a male or a female voice, and that their task was to recognize the items from the list they had just heard. They were informed that some items would be spoken in the same voice as before and some in the other voice, but that their task was to identify the items regardless of whether the voice was the same as that heard at study.

The participants recorded their responses on a sheet of paper with 120 numbered rows that included the following options: no, yes, remember, and know. If the participants gave a "no" response, they waited for the next item. If they gave a "yes" response, they had to circle either remember or know. Instructions for responding "remember" or "know" were closely modeled after those used by Rajaram (1996). A "remember" response was defined as a response made when recognition is accompanied by conscious recollection of the item's occurrence in the study list, the participant again becoming consciously aware of something that was experienced at the time the item was first presented. A "know" response was defined as one made when recognition is accompanied only by strong feelings that the item had indeed been presented in the study list, and not by any conscious recollection of anything that was specifically experienced at the time of its original presentation. The instructions also discouraged the participants from guessing. In Experiment 5, however, the participants were instructed to report guessing. They were instructed that there might be times when they might just have guessed that a test item was one they had heard in the study list. In that case, they were told to circle a "Guess" response option that had been added to the prepared response sheet. At the end of the recognition test, which lasted about $15 \mathrm{~min}$, the participants had to justify a randomly chosen set of two "remember" and two "know" responses to show that they had understood the distinction between them.

\section{RESULTS AND DISCUSSION}

In Table 1, the main results from all five experiments are summarized. The mean proportions of responses for each response category are shown as a function of voice congruency at study and at test. The effects of voice congruency were analyzed statistically using $t$ tests comparing same-voice versus different-voice conditions, separately for each response category in each experiment. To reduce the risk of making a Type I error, the more conservative alpha level of .01 was used for all tests, unless otherwise noted. We do not report statistical analyses involving false alarm rates, although these data were taken into account in the signal detection analyses, which we describe later.

The results from Experiment 1 are shown in the first three rows of Table 1. The purpose of this experiment was to replicate the voice congruency effect and to determine whether, for words, this effect normally occurred in remembering. It is apparent that the experiment did successfully replicate the voice congruency effect and that this effect did indeed occur in remembering. The effect of voice congruency was significant both for overall recognition $[t(31)=3.29]$ and for remembering $[t(31)=4.51]$. There was no indication of any effect in knowing $[t(31)=$ $-.62]$. Experiment 1 therefore replicated for voice congruency the effects in remembering that Rajaram (1996) and Gardiner et al. (2001) had obtained for size congruency.

In Experiment 2, we investigated voice congruency effects using nonwords rather than words. The rationale for the use of nonwords was that they provide less opportunity

Table 1

Mean Proportions of Responses as a Function of Voice Congruency in Experiments 1-5, and Standard Deviations

\begin{tabular}{|c|c|c|c|c|c|c|c|}
\hline \multirow[b]{3}{*}{ Experiment } & \multirow{3}{*}{$\begin{array}{l}\text { Response } \\
\text { Category }\end{array}$} & \multicolumn{4}{|c|}{ Study/Test Congruency } & & \\
\hline & & \multicolumn{2}{|c|}{ Same Voice } & \multicolumn{2}{|c|}{ Different Voice } & \multicolumn{2}{|c|}{ Unstudied } \\
\hline & & $M$ & $S D$ & $M$ & $S D$ & $M$ & $S D$ \\
\hline \multirow[t]{3}{*}{1} & Recognize & .76 & .15 & .67 & .16 & .22 & .10 \\
\hline & Remember & .44 & .14 & .34 & .14 & .06 & .05 \\
\hline & Know & .31 & .12 & .33 & .11 & .16 & .08 \\
\hline \multirow[t]{3}{*}{2} & Recognize & .64 & .17 & .49 & .17 & .29 & .15 \\
\hline & Remember & .28 & .10 . & 21 & .10 & .12 & .10 \\
\hline & Know & .36 & .15 & .29 & .12 & .17 & .10 \\
\hline \multirow[t]{3}{*}{3} & Recognize & .68 & .08 & .50 & .09 & .30 & .11 \\
\hline & Remember & .34 & .07 & .28 & .07 & .09 & .07 \\
\hline & Know & .34 & .10 & .22 & .09 & .21 & .09 \\
\hline \multirow[t]{3}{*}{4} & Recognize & .56 & .15 & .44 & .12 & .34 & .15 \\
\hline & Remember & .18 & .08 & .16 & .07 & .11 & .07 \\
\hline & Know & .38 & .09 & .28 & .08 & .23 & .01 \\
\hline \multirow[t]{4}{*}{5} & Recognize & .63 & .12 & .54 & .11 & .28 & .09 \\
\hline & Remember & .19 & .05 & .17 & .05 & .07 & .04 \\
\hline & Know & .36 & .08 & .27 & .08 & .11 & .05 \\
\hline & Guess & .08 & .05 & .09 & .08 & .10 & .06 \\
\hline
\end{tabular}

Note-Where there were significant voice congruency effects (i.e., $\alpha=.01$ ), mean proportions and standard deviations are shown in bold. 
for meaningful, elaborative processing. For that reason, nonwords present relatively impoverished encoding opportunities that might lead to voice congruency effects in knowing. The results from Experiment 2 are shown in the next three rows of Table 1. It is apparent that there were voice congruency effects in this experiment too, but, in contrast with Experiment 1, an effect seems to have occurred in knowing as well as in remembering. The statistical results support this conclusion for overall recognition $[t(31)=$ 5.75], remembering $[t(31)=5.07]$, and knowing $[t(31)=$ 3.77].

Experiment 3 was designed as a direct replication of Experiment 2, and the results (shown in the next three rows of Table 1) show a similar pattern of differences, although in Experiment 3 the effect in knowing seems appreciably larger. The effect of voice congruency was significant for overall recognition $[t(15)=6.79]$ and for knowing $[t(15)=$ 4.34]. However, in contrast with the results of Experiment 2 , the effect for remembering was only marginally significant $[t(15)=2.26, .01<p<.05]$. This outcome may reflect the reduced power of the test in Experiment 3, because the mean difference between same and different voice conditions here was similar to that in Experiment 2. In view of this, we carried out a further test to compare the differences between same versus different voice in remembering (.34 vs. .28) with the differences between same versus different voice in knowing (.34 vs. .22). The two effects did not differ reliably $[t(15)=1.15]$.

Thus, the results of Experiments 2 and 3 support the hypothesis that under some conditions voice congruency effects may transfer from remembering to knowing. This transfer was less than complete, however, in that there were still significant voice effects in remembering. In Experiment 4 , the aim was to further reduce encoding opportunities by not only presenting nonwords but also adding a divided-attention study task. The results of this experiment are summarized in the next three rows of Table 1, from which it is apparent that voice congruency effects in remembering were greatly reduced. The effect of voice congruency was significant for overall recognition $[t(15)=$ $6.54]$ and for knowing $[t(15)=5.16]$. Despite the small difference in remembering for same and different voice conditions, this difference was also marginally significant $[t(15)=2.26, .01<p<.05]$. In view of this, we carried out a test for differences between the effects in remembering (.18 vs. .16) and the effects in knowing (.38 vs. .28) that was similar to that carried out in Experiment 3. This showed that the effect in knowing was significantly greater than the effect in remembering $[t(15)=2.55]$. Thus, it seems reasonable to conclude that, with divided attention at study, the effect of size congruency occurred mainly in knowing rather than in remembering.

The false alarm rates were quite high in Experiments 3 and 4, especially for the "know" responses, and so Experiment 5 was designed to replicate Experiment 4 but with the addition of a "guess" response category, which was expected to reduce these false alarm rates (Gardiner \& Conway, 1999; Gardiner et al., 2002). The results of Experiment 5 are shown in the last four rows of Table 1 . It is apparent that these results were very similar to those obtained in Experiment 4, except that the false alarm rates for the "know" responses were greatly reduced. There was again an effect of voice congruency, and it was again most evident in knowing. There were significant effects of voice congruency for overall recognition $[t(15)=3.18]$ and for knowing $[t(15)=5.74]$. The effect of voice congruency for remembering was again small but marginally significant $[t(15)=2.15, .01<p<.05]$. The effect in knowing (.36 vs. .27) was significantly greater than the effect in remembering [.19 vs. $.17 ; t(15)=3.76]$. Thus, it seems reasonable to conclude that, as in Experiment 4, with divided attention at study the voice congruency effects occurred mainly in knowing rather than in remembering.

\section{Signal Detection Analyses}

We next describe briefly the results of signal detection analyses for all five experiments using $A$ - estimates of memory strength and $B_{\mathrm{D}}$ estimates of response criteria (Donaldson, 1996). Table 2 shows two sets of estimates for each experiment: those derived from overall recognition responses and those derived only from "remember" responses. The critical test of a unitary trace-strength/ decision-criterion account is not that response criteria will be more lenient for overall recognition than for remem-

Table 2

Mean $A^{\prime}$ and $B_{\mathrm{D}}$ Estimates as a Function of Voice Congruency in Experiments 1-5

\begin{tabular}{|c|c|c|c|c|c|}
\hline \multirow[b]{3}{*}{ Experiment } & \multirow{3}{*}{$\begin{array}{l}\text { Response } \\
\text { Category }\end{array}$} & \multicolumn{4}{|c|}{ Study/Test Congruency } \\
\hline & & \multicolumn{2}{|c|}{ Same Voice } & \multicolumn{2}{|c|}{ Different Voice } \\
\hline & & $A^{\prime}$ & $B_{\mathrm{D}}^{\prime \prime}$ & $A^{\prime}$ & $B_{\mathrm{D}}^{\prime \prime}$ \\
\hline \multirow[t]{2}{*}{1} & Recognize & .85 & .01 & .81 & .21 \\
\hline & Remember & .81 & .89 & .77 & .92 \\
\hline \multirow[t]{2}{*}{2} & Recognize & .76 & .10 & .67 & .37 \\
\hline & Remember & .67 & .88 & .60 & .91 \\
\hline \multirow[t]{2}{*}{3} & Recognize & .77 & .06 & .67 & .37 \\
\hline & Remember & .75 & .89 & .72 & .90 \\
\hline \multirow[t]{2}{*}{4} & Recognize & .68 & .17 & .58 & .38 \\
\hline & Remember & .61 & .93 & .58 & .94 \\
\hline \multirow[t]{2}{*}{5} & Recognize & .76 & .16 & .70 & .36 \\
\hline & Remember & .69 & .96 & .67 & .97 \\
\hline
\end{tabular}


bering, but that estimates of trace strength should be the same regardless of the response criteria used to estimate them. That is, estimates of trace strength can be derived from the most lenient response criteria through the use of overall recognition hits and false alarms, or from the most stringent criteria through the use of only remember hits and false alarms. If there is only one memory trace, these estimates should not differ.

It is apparent from Table 2 that in 9 of the 10 comparisons summarized in the table, $A$ ' estimates derived from overall recognition differed from $A$ ' estimates derived from remembering and that in 8 of those 9 comparisons the estimates for overall recognition were greater than those for remember hits $(p=.02)$. The results of individual $t$ tests (which we will not report in detail) were also significant in all 9 of these comparisons (though in a few instances only when $\alpha=.05$ ). Thus, when knowing was added to remembering, estimates of trace strength increased, which indicates that knowing represents an additional source of memory. These results can therefore be added to many others that point to the same conclusion (see, e.g., Gardiner, 2001; Gardiner et al., 2001; Gardiner et al., 2002).

Apart from that, the results of this analysis add little to the analyses in terms of simple response proportions. Individual $t$ tests for voice congruency effects as measured by these $A^{\prime}$ estimates (which we will also not report in detail) merely reflected those for the simple response proportions and did not materially alter the conclusions to be drawn. Thus, the results of the signal detection analyses serve mainly to allow us to discount the possibility that the changes in awareness with respect to voice congruency effects might be explained simply in terms of decision processes (Hirshman, Fisher, et al., 2002; Hirshman, Lanning, et al., 2002).

\section{GENERAL DISCUSSION}

The primary aim of this series of experiments was to determine how voice congruency effects in recognition memory are related to remembering and knowing under different encoding conditions. Gardiner et al. (2001) had found that whether size congruency effects in recognition memory occurred mainly in remembering or in knowing depended on encoding conditions. With more optimal encoding conditions, such as undivided attention at study, size congruency effects were associated with remembering, replicating results first reported by Rajaram (1996). With less optimal encoding conditions, as with divided attention at study, size congruency effects were associated with knowing.

This impact of encoding conditions on the state of awareness associated with the effects of size congruency strengthens the distinctiveness/fluency account of remembering and knowing that Rajaram (1996) proposed. According to this account, remembering depends on the distinctiveness of the processing, whereas knowing depends on its fluency, regardless of whether that processing is predominantly conceptual or perceptual in nature. From this perspective, the more impoverished the encoding conditions, the more difficult it becomes to achieve distinctive processing; hence, remembering decreases and the perceptual effects of size congruency are associated instead with increased processing fluency.

By the same token, these findings are also consistent with Tulving's (1995) SPI model of the relations between episodic and semantic memory systems. From this perspective, even fairly minimal encoding conditions are sufficient for events to be registered in semantic memory, whereas for events to be registered in episodic memory, encoding has to involve more elaborative and distinctive processing (see also Mangels et al., 2001). Hence, the effects of size congruency may reflect retrieval from either the episodic or the semantic memory system.

Thus, the hypothesis was that voice congruency effects too would occur in remembering with more optimal encoding conditions and in knowing with less optimal encoding conditions. In general, the results provided good support for this hypothesis. The finding that under the optimal encoding conditions of Experiment 1 voice congruency effects occurred in remembering provides further evidence for perceptual effects in remembering (Gardiner et al., 2001; Rajaram, 1996). Under the less optimal encoding conditions of Experiments 2 and 3, in which nonwords rather than words were used, voice congruency effects occurred in knowing as well as in remembering. And, with nonwords and divided attention at study in Experiments 4 and 5, they transferred almost completely from remembering to knowing. By showing that the same kinds of perceptual effects that occur in remembering may also occur in knowing, these findings provide further support for an orthogonal relation between the two states of awareness and the perceptual/conceptual nature of the processing, as was proposed in the distinctiveness/fluency model (Rajaram, 1996). From the perspective of the SPI model (Tulving, 1995), they also strengthen the evidence suggesting that, depending on encoding conditions, events may be independently retrieved from either episodic or semantic memory systems.

It is important to appreciate that it is not inevitably the case that effects that normally occur in remembering will transfer to knowing as encoding conditions become more impoverished. Word frequency effects in recognition memory provide a good counterexample. Several recent studies have suggested that the low-frequency advantage in correct recognition is attributable to more distinctive encoding and, hence, to better recollection, whereas the greater error rate for high-frequency words is attributable to their greater familiarity (see, e.g., Joordens \& Hockley, 2000; Reder et al., 2000). In accordance with this view-and in contrast with earlier dual-process theories that attributed the lowfrequency advantage to increased familiarity (e.g., Mandler, 1980) - this low-frequency advantage occurs in remembering rather than in knowing (Gardiner \& Java, 1990).

Gregg, Gardiner, Karayianni, and Konstantinou (2003) have recently investigated word frequency effects in recog- 
nition memory under divided attention conditions similar to those used by Gardiner et al. (2001) and in the present study. The effects of the attentional manipulation were quite different. With divided attention, there was still a lowfrequency advantage associated with remembering, but it was offset by a high-frequency advantage in knowing, with the net result that the overall word frequency effect disappeared (see also Balota, Burgess, Cortese, \& Adams, 2002; Hirshman, Fisher, et al., 2002; Joordens \& Hockley, 2000; Reder et al., 2000).

Further evidence that the transfer of effects from remembering to knowing with more impoverished encoding conditions might be quite a circumscribed kind of outcome comes from a study by Curran and Hildebrandt (1999). They investigated the generation effect - that is, superior recognition of words generated by participants rather than read by them-when remembering was reduced by means of alcohol. The generation effect is another effect that normally occurs in remembering (Gardiner, 1988). Although alcohol greatly reduced remembering without much affecting knowing, there was no sign of a generation effect emerging in "know" responses. Instead, the generation effect in remembering was just greatly attenuated.

Thus, it seems as though the impact of impoverished encoding conditions in which effects transfer from remembering to knowing depends very much on what kinds of effects are involved. So far, only the perceptual effects have been found to do this. This provides some support for the suggestion that, following such encoding conditions, familiarity-based recognition may largely reflect perceptual processes (Mangels et al., 2001), if only because this transfer of perceptual effects would then be in good agreement with the principles of transfer-appropriate processing (Roediger, 1990). Perhaps conceptual effects will transfer from remembering to knowing only when knowing largely reflects conceptual processes.

In this connection, it is interesting to compare this transfer of perceptual effects from one state of awareness to another with some conceptual effects reported by Conway, Gardiner, Perfect, Anderson, and Cohen (1997). In a study of long-term undergraduate student learning, Conway et al. (see also Herbert \& Burt, 2001) compared students' performance on initial tests of knowledge acquired in lectures with their performance on retests taken some months later, and found an effect that they termed the rememberto-know shift. The tests involved multiple-choice questions for which the students not only had to select an answer but also had to report their memory awareness. The students who scored high on the initial tests reported more remembering than did their fellow students. In the retests, the same high-scoring students reported more knowing than did their fellow students. Thus, knowledge acquisition was dependent on initial good episodic memory, which subsequently translated into good semantic memory.

"Know" responses in the Conway et al. (1997) study, however, were defined as "just knowing," and participants reported feelings of familiarity - that is, feelings of a recent but unremembered encounter-separately. "Know" responses in the standard recognition memory remember/ know paradigm correspond more closely to judgments of this kind of familiarity than to "just knowing" (see Gardiner, Ramponi, \& Richardson-Klavehn, 1998). Feelings of familiarity relating to a recent encounter and "just knowing" are clearly rather different kinds of experiences. Nonetheless, both of these kinds of experiences are expressions of noetic rather than autonoetic consciousness (for further discussion, see Gardiner \& Conway, 1999). Hence, in Tulving's (1995) model, both of these varieties of noetic awareness reflect semantic memory representation and retrieval.

In marked contrast with the schematization of knowledge indicated by the "remember-to-know" shift reported by Conway et al. (1997; see also Herbert \& Burt, 2001), the transfer of perceptual effects from remembering to knowing observed by Gardiner et al. (2001) and in the present study implicates only the most minimal level of representation in semantic memory. It will be important to discover what other effects similarly transfer from remembering to knowing, when knowing reflects this minimal level of representation, and whether, indeed, it is only perceptual effects that do this.

\section{REFERENCES}

Balota, D. A., Burgess, G. C., Cortese, M. J., \& Adams. D. R. (2002). The word-frequency mirror effect in young, old, and early-stage Alzheimer's disease: Evidence for two processes in episodic recognition memory. Journal of Memory \& Language, 46, 199-226.

Church, B., \& Schacter, D. L. (1994). Perceptual specificity of auditory priming: Memory for voice intonation and fundamental frequency. Journal of Experimental Psychology: Learning, Memory, \& Cognition, 20, 521-533.

Conway, M. A., Dewhurst, S. A., Pearson, N., \& Sapute, A. (2001). The self and recollection reconsidered: How a "failure to replicate" failed and why trace strength accounts of recollection are untenable. Applied Cognitive Psychology, 15, 673-686.

Conway, M. A., Gardiner, J. M., Perfect, T. J., Anderson, S. J., \& Cohen, G. M. (1997). Changes in memory awareness during learning: The acquisition of knowledge by psychology undergraduates. Journal of Experimental Psychology: General, 126, 393-413.

Craik, F. I. M., \& KIrSner, K. (1974). The effect of speaker's voice on word recognition. Quarterly Journal of Experimental Psychology, 26, 274-284.

Curran, H. V., \& Hildebrandt, M. (1999). Dissociative effects of alcohol on recollective experience. Consciousness \& Cognition, 8, 497-509.

DonALDSON, W. (1996). The role of decision processes in remembering and knowing. Memory \& Cognition, 24, 523-533.

GARDINER, J. M. (1988). Functional aspects of recollective experience. Memory \& Cognition, 16, 309-313.

GARDInER, J. M. (2001). Episodic memory and autonoetic consciousness: A first-person account. Philosophical Transactions of the Royal Society of London: Series B, 356, 1351-1361.

Gardiner,J. M., \& Conway, M. A. (1999). Level of processing and varieties of experience. In B. H. Challis \& B. M. Velichkovsky (Eds.), Stratification in cognition and consciousness (pp. 237-254). Amsterdam: John Benjamins.

Gardiner, J. M., Gawlik, B., \& Richardson-Klavehn, A. (1994). Maintenance rehearsal affects knowing, not remembering; elaborative rehearsal affects remembering, not knowing. Psychonomic Bulletin \& Review, 1, 107-110.

Gardiner, J. M., Gregg, V. H., Mashru, R., \& Thaman, M. (2001). Impact of encoding depth on awareness of perceptual effects in recognition memory. Memory \& Cognition, 29, 433-440. 
GARDINER, J. M., \& JAVA, R. I. (1990). Recollective experience in word and nonword recognition. Memory \& Cognition, 18, 23-30.

Gardiner, J. M., Kaminska, Z, Dixon, M., \& JaVA, R. I. (1996). Repetition of previously novel melodies sometimes increases both remember and know responses in recognition memory. Psychonomic Bulletin \& Review, 3, 366-371.

Gardiner, J. M., Ramponi, C., \& Richardson-Klavehn, A. (1998). Experiences of remembering, knowing, and guessing. Consciousness \& Cognition, 7, 1-26.

Gardiner, J. M., Ramponi, C., \& Richardson-Klavehn, A. (1999). Response deadline and subjective awareness in recognition memory. Consciousness \& Cognition, 8, 484-496.

Gardiner, J. M., Ramponi, C., \& Richardson-Klavehn, A. (2002). Recognition memory and decision processes: A meta-analysis of remember, know, and guess responses. Memory, 10, 83-98.

Gardiner, J. M., \& Richardson-KLAVEhn, A. (2000). Remembering and knowing. In E. Tulving \& F. I. M. Craik (Eds.), Handbookofmemory (pp. 229-244). New York: Oxford University Press.

GoldiNGER, S. D. (1996). Words and voices: Episodic traces in spoken word identification and recognition memory. Journal of Experimental Psychology: Learning, Memory, \& Cognition, 22, 1166-1183.

GregG, V. H., \& Gardiner, J. M. (1994). Recognition memory and awareness: A large cross-modal effect on "know" but not "remember" responses following a highly perceptual-orienting task. European Journal of Cognitive Psychology, 6, 131-147.

GregG, V. H., Gardiner, J. M., Karayianni, I., \& Konstantinou, I. (2003). Reversal of the word frequency effect in recognition memory: A high frequency advantage in the accuracy of knowing following restricted encoding. Manuscript submitted for publication.

Herbert, D. M. B., \& Burt, J. S. (2001). Memory awareness and schematization: Learning in the university context. Applied Cognitive Psychology, 15, 617-637.

Hirshman, E., Fisher, J., Henthorn, T., Arndt, J., \& Passannante, A. (2002). Midazolam amnesia and dual-process models of the wordfrequency mirror effect. Journal of Memory \& Language, 47, 499-516.

Hirshman, E., Lanning, K., Master, S., \& Henzler, A. (2002). Signaldetection models as tools for interpreting judgements of recollections. Applied Cognitive Psychology, 16, 151-156.

Hirshman, E., \& Master, S. (1997). Modeling the conscious correlates of recognition memory: Reflections on the remember-know paradigm. Memory \& Cognition, 25, 345-351.

Inoue, C., \& Bellezza, F. S. (1998). The detection model of recognition using know and remember judgments. Memory \& Cognition, 26, 299-308.

JACOBY, L. L. (1991). A process-dissociation framework: Separating automatic from intentional uses of memory. Journal of Memory \& Language, 30, 513-541.

Jacoby, L. L., Yonelinas, A. P., \& Jennings, J. M. (1997). The relation between conscious and unconscious (automatic) influences: A declaration of independence. In J. D. Cohen \& J. W. Schooler (Eds.), Scientific approaches to the question of consciousness (pp. 13-47). Hillsdale, NJ: Erlbaum.

Joordens, S., \& HockLey, W. E. (2000). Recollection and familiarity through the looking glass: When old does not mirror new. Journal of Experimental Psychology: Learning, Memory, \& Cognition, 26, 15341555 .

KuČERA, H., \& FrAnCIS, W. N. (1967). Computationalanalysis of present day American English. Providence: Brown University Press.

MANDLER, G. A. (1980). Recognizing: The judgment of previous occurrence. Psychological Review, 87, 252-271.

Mangels, J. A., Picton, T. W., \& Craik, F. I. M. (2001). Attention and successful episodic encoding: An event-related potential study. Cognitive Brain Research, 11, 77-95.
MÄNTYLÄ, T. (1997). Recollection of faces: Remembering differences and knowing similarities. Journal of Experimental Psychology: Learning, Memory, \& Cognition, 23, 1203-1216.

Palmeri, T. J., Goldinger, S. D., \& Pisoni, D. B. (1993). Episodic encoding of voice attributes and recognition memory. Journal of Experimental Psychology: Learning, Memory, \& Cognition, 19, 309-328.

Pilotti, M., Bergman, E. T., Gallo, D. A., Sommers, M., \& RoediGER, H. L., III (2000). Direct comparison of auditory implicit memory tests. Psychonomic Bulletin \& Review, 7, 347-353.

Pilotti, M., Gallo, D. A., \& Roediger, H. L., III (2000). Effects of hearing words, imagining hearing words, and reading on auditory implicit and explicit memory tests. Memory \& Cognition, 28, 1406-1418.

RAJARAM, S. (1993). Remembering and knowing: Two means of access to the personal past. Memory \& Cognition, 21, 89-102.

Rajaram, S. (1996). Perceptual effects on remembering: Recollective processes in picture recognition memory. Journal of Experimental Psychology: Learning, Memory, \& Cognition, 22, 365-377.

RAJARAM, S. (1998). The effects of conceptual salience and perceptual distinctiveness on conscious recollection. Psychonomic Bulletin \& Review, 5, 71-78.

Rajaram, S., \& Geraci, L. (2000). Conceptual fluency selectively influences knowing. Journal of Experimental Psychology: Learning, Memory, \& Cognition, 26, 1070-1074.

Rajaram, S., Hamilton, M., \& Bolton, A. (2002). Distinguishing states of awareness from confidence during retrieval: Evidence from amnesia. Cognitive, Affective, \& Behavioral Neuroscience, 2, 227-235.

Reder, L. M., Nhouyvanisvong, A., Schunn, C. D., Ayers, M. S. Angstadt, P., \& Hiraki, K. (2000). A mechanistic account of the mirror effect for word frequency: A computational model of remember/ know judgments in a continuous recognition paradigm. Journal of Experimental Psychology: Learning, Memory, \& Cognition, 26, 294-320.

Roediger, H. L., III (1990). Implicit memory: Retention without remembering. American Psychologist, 45, 1043-1056.

Rotello, C. M., Macmillan, N. A., \& Reeder, J. A. (in press). Sum difference theory of remembering and knowing: A two-dimensional signal detection model. Psychological Review.

Schacter, D. L., \& Church, B. A. (1992). Auditory priming: Implicit and explicit memory for words and voices. Journal of Experimental Psychology: Learning, Memory, \& Cognition, 18, 915-930.

Sheffert, S. M., \& Fowler, C. A. (1995). The effects of voice and visible speaker change on memory for spoken words. Journal of Memory \& Language, 34, 665-685.

Tulving, E. (1983). Elements of episodic memory. Oxford: Oxford University Press.

Tulving, E. (1985). Memory and consciousness. Canadian Psychology, 26, 1-12.

Tulving, E. (1995). Organization of memory: Quo vadis? In M. S. Gazzaniga (Ed.), The cognitive neurosciences (pp. 839-847). Cambridge, MA: MIT Press.

Tulving, E. (2002). Episodic memory: From mind to brain. Annual Review of Psychology, 53, 1-25.

YonelinAs, A. P. (2002). The nature of recollection and familiarity: A review of 30 years of research. Journal of Memory \& Language, 46, 441-517.

Yonelinas, A. P., Dobbins, I., Szymanski, M. D., Dhaliwal, H. S., \& KING, L. (1996). Signal-detection, threshold, and dual-process models of recognition memory: ROCs and conscious recollection. Consciousness \& Cognition, 5, 418-441.

(Manuscript received February 19, 2003; revision accepted for publication May 30, 2003.) 